\title{
Seeds
}

of

hope

The improved varieties of staple crops which hold out the eventual hope of feeding the world's growing population, will depend for some of their most valuable characteristics on the genetic raw material contained in the old indigenous varieties of crops cultivated by peasant farmers for thousands of years. But this pool of inherited variation is rapidly drying up because of the success of the very varieties it helped to create. The primitive 'landraces' and their wild relatives have in the past proved an invaluable source of resistance (worth many millions of pounds) to serious pests and diseases, and have provided genes for many other desirable characters such as improved nutritional quality and adaptations to drought or cold. The serious implications of the rapid disappearance of this reservoir of valuable genes is now recognised in many quarters, and work to conserve the variation which remains is under way throughout the world. Eleanor Lawrence reports on one of the first institutes specifically set up to tackle this problem as it enters its second decade.

THE Genetic Resources Unit established by the FAO within the Aegean Regional Agricultural Research Institute (ARARI) just outside Izmir, on Turkey's Aegean coast, started life in 1964 as an experiment unique at the time. It was the first such unit specifically set up to deal with the collection, storage and evaluation of the rapidly vanishing genetic variation in cultivated crops within a region holding a large part of the remaining stocks of primitive cultivars and wild relatives of some of the most important temperate crops -wheat, barley and grain and forage legumes.

The concept of a 'gene bank' itself was hardly new even in the early 1960s. Plant breeders had collected useful material from all over the world to

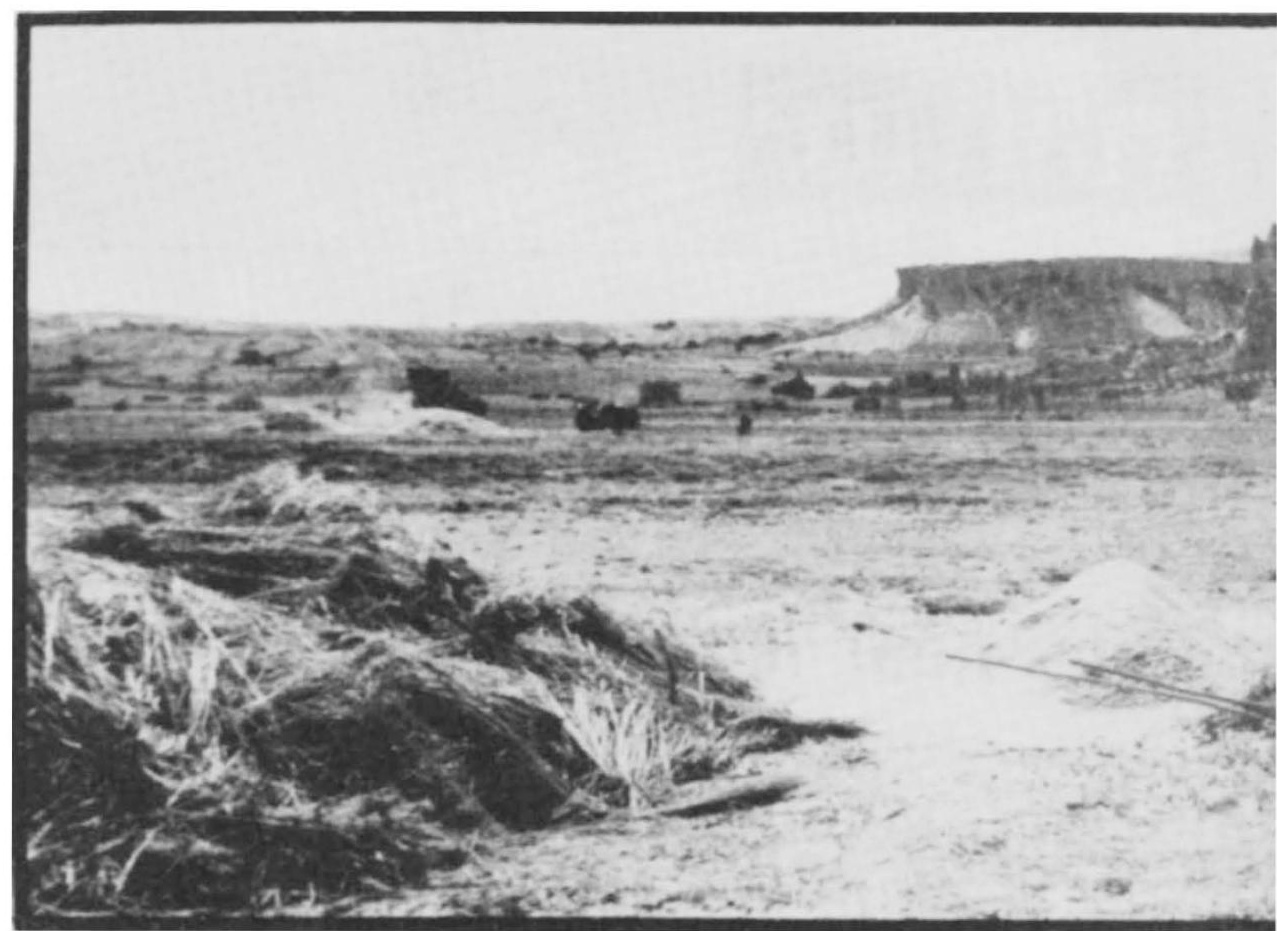

incorporate into plant breeding trials, but material not of immediate use had often been discarded. Large reference collections of seed of important crops were held at the National Seed Storage Laboratory at Fort Collins in Colorado, and in the USSR, where the now irreplaceable collections made by N. I. Vavilov and his coworkers in the 1920s and ' 30 s were kept in Leningrad and at other centres throughout the country. Collections of various types and sizes were also held throughout the world.

But there were as yet no mediumsized institutes, actually located in the countries where the greatest genetic diversity occurred, which had as their primary aim the systematic collection, and on-the-spot conservation and study, of valuable seed material, with the additional aim of screening and describing the material and making it freely accessible.

The importance of the Near East (stretching from Turkey to Pakistan in the east and Lebanon in the south) as a centre of diversity for many temperate crops stems from its complex geography and its long continuous history of agriculture. The Near East is the cradle of modern 'western' agriculture, based on wheat and barley as staples, which were first cultivated there some 10,000 years ago. Archaeological evidence shows that a mixed agriculture based on wheat and barley had developed throughout the region by the 8 th century BC. Barley, emmer wheat (tetraploid Triticum dicoccum, a relative of the modern durum wheats), the modern hexaploid bread wheats ( $T$. aestivum) and the diploid einkorn wheat ( $T$. monococcum), still cultivated in parts of Turkey today, have all been found at archaeological sites dated be- tween 6000 and $7000 \mathrm{BC}$.

But today, according to a survey carried out by FAO and the International Biological Programme published in 1973, improved varieties of both durum and aestivum wheat have very nearly replaced local cultivars except for remnants in the more remote regions. The wild progenitors of both wheat and barley can still be found and are even increasing in localities where they happen to be within protected 'national park' areas. 'Today wild barley

If this gene pool of inherited variation built up over thousands of years of evolution, selection and diversification into a wide range of habitats, is allowed to disappear completely, the plant breeder's ability to respond to a changing world situation will be severely restricted. These traditional 'landraces' and their wild relatives are often the only source of resistance genes to a wide variety of serious pests and diseases, such as stem rust in wheat. The old landraces are sometimes not very productive, and some do not respond to fertiliser treatment, but locally adapted populations can withstand conditions of drought or cold for instance which would soon lay low most modern varieties. These characteristics are needed to incorporate into breéding programmes with the generally more productive, modern varietics. Also, with fertilisers and pesticides growing more expensive each year, modern varieties which depend for their high yield on generous inputs of fertilisers may become less attractive. Traditional cultivars which produce good yields under less favourable conditions may prove a more rational basis for future breeding programmes flourishes in the ruins of Ephesus. 


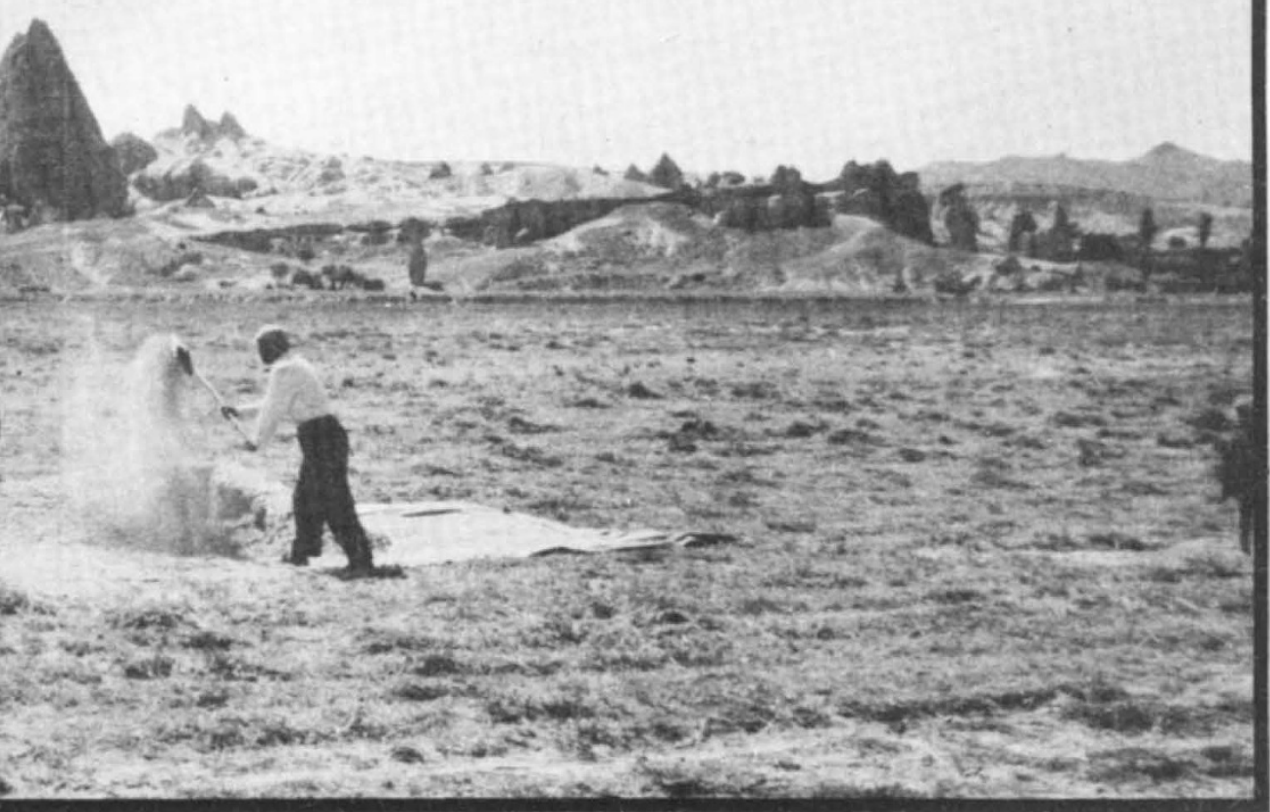

for some areas.

In the decades since the Second World War, Turkey has seen widespread changes in agricultural practice. Changes in land use, introduction of improved varieties and modern methods of agriculture including the use of herbicides for weed clearance, have hastened the disappearance of the old locally-adapted populations.

In 1961, the Turkish government asked for international aid to research into problems posed by the changeover to modern systems of agriculture. In 1963 the United Nations Special Fund (now incorporated into the UN Development Programme) allocated funds and with FAO as the executive agency the 'Izmir Project' began. The Turkish request for aid coincided with FAO's own wish to establish a centre for the collection, study and distribution of forage legumes and grasses, and also with a growing consciousness of the urgent need to survey and collect rapidly disappearing germplasm of important crops. Over the nine years during which the project was financed by UNSF/UNDP, the Turkish government provided a total of $\$ 980,000$ worth of land and staff salaries plus $\$ 110,000$ in cash, and the UN around $\$ 1,290,000$.

The original aim was to establish a Crop Research and Plant Introduction Centre, which as well as carrying out genetic resource surveys and conservation would maintain and initiate breeding programmes and also serve as the point of introduction for new varieties entering the country from abroad. The introduction of plant material from another country is always a risky operation because of the possibility of disease being brought in accidentally. Quarantine procedures for screening incoming material and certifying outgoing seed as disease free are an important part of the work of any centre involved with the distribution of plant material. It was also essential for a unit concerned with genetic resource conservation to keep a finger on the pulse of plant introduction so that they could foresee when the introduction of new varieties into previously undeveloped areas might threaten valuable sources of primitive cultivars.

But the early days of the project were dogged by organisational problems. At the time of its establishment, the Turkish government was also in the process of setting up its own agricultural research institute on the same site using the same funds and facilities provided for the FAO/UNSF programme. It proved logistically impossible to keep the two elements separate, and the original interpretation of the project by FAO as being one primarily of building an institute with an essentially international outlook for the collection, conservation and use of crop genetic resources became to some extent engulfed in the Turkish aim of building an institute of much wider and more immediate value to Turkish agriculture. This was recognised in a merger with the Ministry of Agriculture institute, the present ARARI, in 1967 and the present status of the genetic resources unit within ARARI. From 1970 until UNDP ended its financial aid in 1973, all UNDP/FAO funds were concentrated on the development of this discrete unit within the institute.

The original programme also proved to be overambitious given the limited financial resources and organisational difficulties. The present efficient and streamlined genetic resources unit has, for the time being, had to discard its original plans for full evaluation of the - material collected and now concentrates $\rightarrow$ on collection, storage, and computer documentation of the extensive herbarium and seed collections.

Since 1968, there has been a systematic collecting programme in crops particularly endangered by the changing $\circ$ patterns of agriculture. More than 2,600 samples of cereals, 3,759 samples है. of grain and forage legumes, 615 samples of vegetable and spice crops and 1,513 samples of 'industrial' crops (including over a thousand samples of opium poppy seeds) have been collected from all over Turkey; additional accessions have been received from other countries, and deposited in the excellent cold storage facilities completed in 1968.

The poppy seed collections were made in 1972, under the impending ban on opium poppy cultivation. No collections had been made previously so when the government ban was announced an emergency collection of seed stocks was mounted. Although FAO does not condone the traffic in opium, Papaver somniferum and $P$. bracteum are also important oil seed crops in more than 2,000 villages in Central Anatolia and it was hoped that varieties with high oil content and low morphine content could be selected for restocking. With the full cooperation of the government, local agricultural extension staff were quickly trained in the basic techniques of collecting and over 1,000 samples were gathered in the one season before cultivation stopped.

This exercise also proved an excellent example of the greater efficiency of collections organised and carried out by trained local staff, familiar with the terrain, language and customs of the country. The one-off expeditions mounted by foreign teams, unfamiliar with country and language can sometimes prove unproductive, and one of the roles of the Izmir centre has been to provide support and advice for the many expeditions which visit Turkey, attracted by the diversity of its natural and cultivated flora.

A survey and collection of the wild and traditional varieties of fruit and nut trees, such as almond, walnut, apple and peach, which were first cultivated in the Near East and grow wild in Turkey, has also been made. Although these are not staple crops, they are particularly vulnerable to changing land usage. The traditional mixed orchards where the old cultivars are grown are not being replaced, and large commercial plantations of new varieties are being planted instead. The wild species are also disappearing rapidly. Unlike herbaceous plants, tree germplasm is often difficult to conserve 
as seed. A living collection assembled at Izmir was finally abandoned when it proved too difficult to maintain and evaluate the living trees in conditions far removed from those to which they were adapted, and attention was instead concentrated on selecting the best lines as a basis for varietal improvement. In situ preservation in protected areas probably gives the best chance of preserving the wild varieties.

The ending of UNDP aid in 1973 marked another change in emphasis for the Izmir centre. Since 1970 the international contributions had gone solely to the genetic resource unit, and this now continues with funds from the Swedish International Development Authority through FAO, which have been promised until mid-1976. At the same time, the scope of the genetic resource project was formally widened to take in the neighbouring countries of Syria, Iraq, Iran, Afghanistan and Pakistan, under the title of the Near East Project, which has now been in progress for one year, and aims, with Izmir as a focal point, to coordinate the national efforts in these countries, all important areas of genetic diversity.

The future role of Izmir as the main regional centre is now in some doubt, however, despite its excellent technical facilities, scientific record and core of highly trained, experienced Turkish staff. The problems arise from its present position within a government-controlled institute, where although funded internationally, it is still under the ultimate control of the director of the ARARI, and therefore not completely independent.

Financial support for the Near East Project after mid-1976 is to be channelled through the newly-established International Board for Plant Genetic Resources (IBPGR) which is considering an alternative for the regional centre to serve this programme. In the present reappraisal of world-wide genetic resource conservation at present being carried out by the IBPGR with a view to linking existing programmes into a global network, it would prefer where possible that the regional centres be autonomous and be able to take a truly international view of their essential function of making the seeds they collect and store freely available. The Consultative Group on International Agricultural Research, the parent body of the IBPGR, is setting up a new international agricultural research centre to serve the Near and Middle East in the Lebanon and this might prove a satisfactory location for the regional centre for genetic resource conservation as well, with Izmir continuing as a national centre -perhaps under international funding if necessary.

The Izmir project was a milestone in

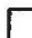

\section{Distribution of seed samples}

$\begin{array}{rrrr} & \text { Turkey } & \text { Abroad } & \text { Total } \\ 1967 & 2,975 & 160 & 3,230 \\ 1968 & 214 & 2,624 & 3,214 \\ 1969 & 1,473 & 265 & 3,214 \\ 1970 & 3,668 & 195 & 1,738 \\ 1971 & 3,474 & 1,672 & 5,146 \\ 1972 & 2,186 & 976 & 3,062 \\ 1973 & 447 & 1,578 & 2,025\end{array}$

Over the years samples of about $75 \%$ of the collections have been sent overseas to scientists and plant breeders on request, with the greatest demand being for wheat, barley and grain legumes. Complete duplicate collections of the cereals have been sent to Canada, chickpeas to India, Holland and the Lebanon, lentils to Argentina and the Lebanon and broad beans to Sweden, East Germany, the United States and Australia. When seeds are sent they are always accompanied by requests that any information on performance and characteristics be returned so that records can be kept up to date.

the transition of genetic resource conservation from a state of individual effort into an internationally coordinated effort, but like many pioneer projects is now hampered by limitations imposed by its origin at a time when the problems of organising genetic resource work on such a scale were imperfectly appreciated.

Another candidate which has been put forward as an alternative regional centre is Ege University near Izmir.

There would be many advantages in locating a centre at Ege, which already has a good department of agriculture, existing collections and facilities including cold storage. Future work on genetic resources, once the initial urgent need for collection has been satisfied, can be usefully diversified into basic research in plant genetics, taxonomy, pathology and ecology which will illuminate the potential of the collected material for use in plant breeding programmes. The present FAO Proiect Officer feels that two projects especially would be particularly appropriate. As legumes always grow naturally in a symbiotic association with nitrogen-fixing rhizobia, which are specific for different species and probably as genetically variable as their plant hosts, a gene bank of rhizobia complementary to the legumes seems essential for the conservation of the natural symbiotic system, and would also prove invaluable for bacterial geneticists who are now trying to breed more efficient strains of rhizobia and attempting to extend their host range. The UN Environment Programme is considering plans at present for the international coordination of Rhizobium collections.

Such a centre would also be an ideal base for work in the variation found between different races of plant pathogenic fungi, which poses a problem for the breeder trying to incorporate resistance into the plant, and for surveys of the extent of disease resistance within areas where it has arisen naturally.

A completely new regional genetic resource centre, wherever it is eventually located, will, however, take some time to put into commission and time is in short supply as far as exploration and collection are concerned. The facilities at Izmir will certainly be needed more than ever in the next year or so. Most of the Near East countries have vigorous programmes of agricultural improvement, which within the next decade will further reduce the areas where the older varieties still remain.

Other changes in the Near East Project may be envisaged under future IBPGR funding. The anomalous position of the oil producers Iran and Iraq as recipients of international aid is unlikely to continue. Although the international organisations will be happy to provide expert help and training facilities for young scientists, it is hoped that Iran and Iraq can be persuaded to become contributors along with the other donor countries which comprise mainly the industrialised nations. Although scientists within these countries are fully aware of the necessity to conserve their remaining sources of variation in cultivated crops, it is sometimes difficult to persuade governments that such essentially long term proiects should be supported. But the Izmir Project showed that for a comparatively modest sum. comnared with the thousands of millions of dollars often spent on prestige technology, irreplaceable sources of variation can be safely banked for the future. 